\title{
Implementation Barriers of Industrial Symbiosis: A Systematic Review
}

\author{
Linda Kosmol \\ Technische Universität Dresden, Germany \\ linda.kosmol@tu-dresden.de
}

\author{
Lena Otto \\ Technische Universität Dresden, Germany \\ lena.otto@tu-dresden.de
}

\begin{abstract}
Industrial symbiosis describes a regional inter-firm approach towards a more sustainable industry. However, the implementation of industrial symbiosis is hampered by a multitude of various barriers. Although prior work has dealt with identifying barriers, an encompassing overview is missing to date. Therefore, in this paper, barriers were identified by the means of a literature review and analyzed through qualitative content analysis. In total, 402 barriers for the implementation of industrial symbiosis were identified. They were grouped into nine categories: economic, technology, financial (hard, quantifiable factors); cooperation, management, knowledge, information (soft factors, which are difficult to quantify); policy/regulation, and public/market (contextual factors). The insights gained can be used to develop strategies and tools for further development and advancement of current industrial symbiosis practice to overcome existing barriers.
\end{abstract}

\section{Introduction}

In the pursuit of a more sustainable industry and society, the concept of 'industrial symbiosis' has become increasingly popular in recent years [1], [2]. Industrial symbiosis refers to economically and ecologically motivated, regional inter-firm cooperation and collaboration between industrial companies [3], [4]. It comprises various exchange- or sharing-based business models in order to make full use of underutilized resources, such as industrial by-products (e.g., material, water, energy), logistics, capacities, space, personnel, expertise or knowledge [4], [5]. Through cooperation, the participating companies gain economic advantages (e.g., added sales), while reducing the environmental impact of their industrial activities (e.g., reduced primary energy consumption). As geographic proximity is considered a success factor, this practice is commonly established in industrial parks. Conventional industrial parks in which the local companies adopt symbiotic behavior and commit to sustainable development policies are so-called 'industrial ecosystems' or 'eco-industrial parks' (EIP) [6], [7].

However, uncovering and implementing symbiotic opportunities is a challenging task [8], [9], and information and communication technology (ICT), designed to support this, is also facing a variety of challenges [10], [11]. Many studies report on a number of barriers (defined as "a circumstance or obstacle that keeps people [...] apart or prevents [...] progress" [12]) that have to be overcome in order to successfully establish industrial symbiosis and eco-industrial parks. To identify barriers of industrial symbiosis, prior work has applied various methods (e.g., case studies (e.g., [13]), interviews (e.g., [14]), or surveys (e.g., [15])) in various settings (e.g., different industries and countries). Frequently encountered barriers are technical, economic and regulatory as well as information and cooperation issues [8], [16], [17]. Each individual work contributes to the overall understanding of the multitude of barriers of industrial symbiosis. However, the following aspects remain problematic:

- Barriers are in some cases rather vague or unspecified (e.g., 'regulatory issues' [18]) leading to a limited understanding of occurring barriers.

- Underlying triggering factors of barriers are assigned to different categories in different studies (e.g., informational factors to the categories 'cooperation' and 'trust' [8], [19] or 'information' [8], [16]) making the comparability and cause and effect analysis of these barriers difficult. Especially informational, managerial and social aspects are often not separated clearly.

- Industrial symbiosis is a complex system due to its context dependency and the interdependency of multiple actors, processes and technologies [20]. Accordingly, its barriers are also interwoven and complex. While the diversity of barriers provided by the literature reflects the contextual nature of industrial symbiosis, often only an excerpt of potential barriers is offered and interdependencies between barriers are hardly considered.

In order to develop strategies and (ICT) tools for further and easier development of industrial symbiosis, it is necessary to provide a comprehensive, structured, 
in-depth overview of potential barriers. Such an encompassing overview needs to address the aforementioned issues and is missing to date. Only with such an overview and the proposal for a uniform categorization of barriers, their relevance, perception and impact can be measured. In addition, a clear differentiation of barriers and the investigation of their interdependencies and their impact on cooperation may help to develop strategies and tools capable of mitigating multiple barriers at the same time.

Therefore, we provide such an overview by means of a systematic literature review [21], in which we consolidate the key scientific contributions in the heterogeneous field of barrier research in industrial symbiosis. The barriers identified are further analyzed and categorized using a qualitative content analysis according to Mayring [22].

The remainder of the paper is structured as follows. The theoretical background is given in the next section. Section 3 describes our approach. Section 4 presents the results of our study. These results and the limitations of our work are discussed together with opportunities for further research in Section 5, before concluding the paper.

\section{Theoretical Background}

Industrial symbiosis and its implementation as EIP are recognized as a complex (adaptive) system [20]. The complexity results from the multitude and diversity of system elements (e.g., firms, technologies) and their interaction (e.g., communication, cooperation). Adaptive refers to the ability of the elements to learn and adapt their behavior (e.g., decisions) to their environment. To investigate and understand the complexity and emergence of these systems, researchers examine various, mostly socio-economic or ecotechnological aspects using models, simulations and frameworks that apply systems theory/engineering [23], [24]. However, a combined investigation of socioeconomic and eco-technological perspective is rare.

With the increasing support of ICT [10], [25], [26] in industrial symbiosis/EIP, the perspective of sociotechnical systems is added, which needs to be considered. So far, industrial symbiosis and EIPs have been an issue primarily addressed by engineering domains. However, the higher the level and scale of ICT support, the more important it becomes to incorporate the knowledge and experience of information systems research. This could help to provide a more holistic view of the (ICT) systems' structure and behavior.

\section{Research Method}

We conducted a systematic literature review to identify barriers of industrial symbiosis. Instead of conducting the search in leading journals exclusively, we searched in different databases to avoid bias [21]. AISeL and IEEEXplore were chosen as they represent the information systems community, and Scopus and EBSCOhost, as they cover additional research areas due to their interdisciplinary character.

The search string combined "industrial symbiosis" and the similar concept of "eco-industrial park" with "barrier". Synonyms for "barrier" were tested for results and included as far as they led to additional relevant articles. The search was conducted within title, abstract and keywords as the terms should appear in one of the three fields if the topic is a major one in the paper analyzed: ("industrial symbiosis" OR "eco-industrial park") AND (barrier OR obstacle OR limiter).

Conducting the search in May 2019 led to 137 records, which contained 49 duplicates. For each record, title and abstract were read and assessed by both authors independently to ensure that they met the inclusion criteria. Articles were included if they met the purpose of our study, i.e., focus at least partly on barriers for industrial symbiosis. Furthermore, each article included needed to be available in English. Only peer-reviewed articles were considered. The method applied or the country in which the study was investigated were not used as in- or exclusion criteria. Afterwards, the remaining full-texts were also assessed for eligibility by both authors independently. The summarized flow of information can be found in Figure 1 according to the Preferred Reporting Items for Systematic Reviews and Meta-Analyses (PRISMA) flow chart [27].

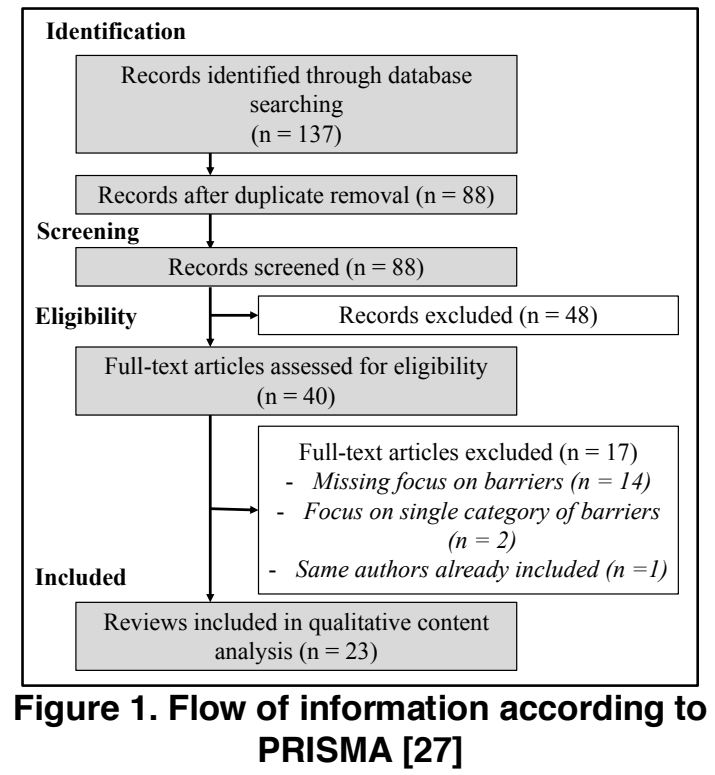


All included full-text articles were analyzed using Mayring's [22] qualitative content analysis. The specific barriers were taken from the literature and recorded in a list. The barriers were subsequently categorized inductively and bottom-up, without using existing categories. Similar barriers (e.g., missing technical knowledge, lack of market knowledge) were first assigned to a subcategory (e.g., lack of knowledge). Similar subcategories (e.g., lack of knowledge, knowledge sharing) were then assigned to categories describing the whole group of barriers (e.g., knowledge). Finally, the categories were grouped into factors (e.g., soft factors), which represent the underlying patterns triggering each individual barrier. This categorization process was done for each barrier, until all barriers were categorized. Whenever the existing categories were not sufficient, a new category describing the barriers related was introduced.

The analysis was done collaboratively by both authors. During the analysis, an unambiguous assignment of barriers to triggering factors was the goal in order to clearly identify and delineate the related factors. However, some barriers are caused by several factors and have therefore been assigned to more than one category. For example, costs are both economic and financial barriers, but there are different types of costs. While continuous costs, such as transport costs, have a long-term impact on a company's economic performance, transaction or investment costs, which are primarily one-time, are more likely to affect a company's financing situation.

\section{Results}

All in all, 402 barriers could be extracted within the 23 articles identified ([8], [9], [13]-[19], [28]-[41]). These are evaluated concept-centrically in the following [21]. An author-centric overview of the literature is given in Table 1 in Section 4.5. The inductive categorization led to nine categories (displayed in bold in the following) and further subcategories (displayed in italics). While some of the categories and subcategories describe barriers related to numbers or quantities, others are more or less directly relevant for individual firms within the industrial symbiosis. To understand the nature of the barriers analyzed, we further classified the factors into three broad topics, i.e., hard factors (which tend to be easily quantifiable) and soft factors (which are difficult to quantify) related to the industrial symbiosis itself and contextual factors around the symbiosis. Each factor is described by relating categories and subcategories, using the specific barriers as examples and definitions for each factor.

\subsection{Hard factors}

129 of the identified barriers (32\%) are related to hard, quantifiable factors (see Figure 2). The biggest group of barriers are economic factors (54 barriers), followed by technology related (53 barriers) and financial ones (22 barriers).

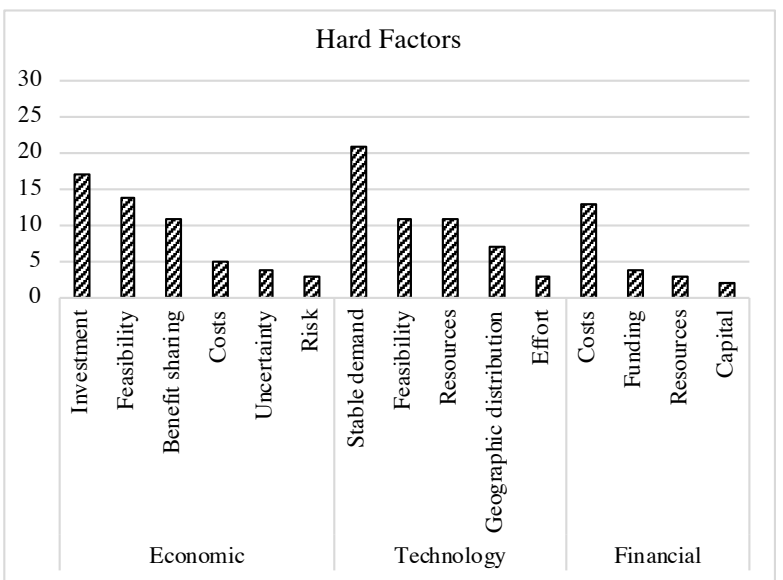

Figure 2. Number of barriers per category and subcategory for hard factors

The economic category consist of barriers related to investment (e.g., different investment cycles [28], [29], [33] and change costs [14], [19], [31]), feasibility (e.g., conflicts with financial gains [15]), benefit sharing (e.g., difficulty to assign value [38] or to identify cost-benefits ex ante [14], [29], [33]), and costs (e.g., related to promotion [31] or transport [14], [38]). Additionally, the categories uncertainty (e.g., uncertain profits [33] and margins [28]) and risk [40] belong to the economic category.

The category technology consists of the subcategories stable demand (e.g., lack of necessary quality, quantity and continuity of material and energy flows (e.g., [29], [33], [34])), feasibility (e.g., material is unsuitable for reuse [28]), and resources (e.g., lack of technical resources [15], [35], space [41] or pretreatment technologies [34]). Furthermore, geographic distribution and effort relate to technology. While geographic distribution is the reason for technological issues due to distances [28], effort describes changes in flows [40], procedures and processes [14].

The financial category includes costs, funding, resources and capital. Costs include, among others, transaction [9], [28], [33] or investment costs (e.g., [9], [36], [39]). While funding describes, e.g., the lack of funding [17], [31] or research funding [15], resources are mainly related to lacking financial resources [16], [35]. Moreover, the shortage of internal and the 
acquisition of external capital [28] are additional barriers to be considered.

\subsection{Soft factors}

About half of all barriers ( 197 barriers $=49 \%$ ) were categorized into soft factors (see Figure 3), which are difficult to quantify. These are cooperation (79 barriers), management ( 56 barriers), knowledge ( 32 barriers), and information (30 barriers).

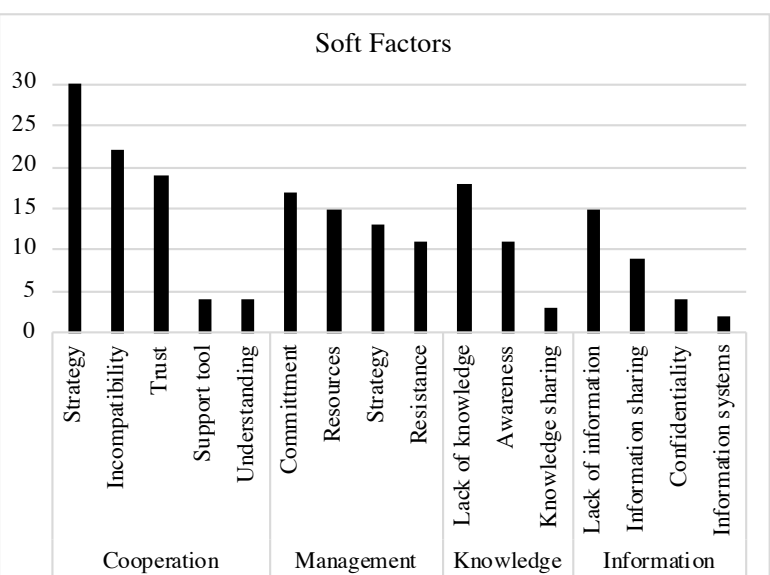

Figure 3. Number of barriers per category and subcategory for soft factors

As industrial symbiosis comprises inter-firm partnerships, cooperative issues may arise due to differences in the involved companies' strategies (e.g., aversion (e.g., [17], [28], [33]), unwillingness [41] and discontinuity [29] regarding collaboration, conflicts of interest and objectives [17] or lack and difficulty of multi-actor decision making [9], [19]). Further organizational incompatibilities result from the structure and current situation of the potential partners (e.g., bound by old contracts [41], different culture [19], [32], [38], differences in power structure and company size (e.g., [19], [40], [41])). In addition, a lack of trust (e.g., due to competitive attitudes [29], [39] or social isolation [28]), a lack of support tools (e.g., information systems for communication, coordination and collaboration [9], [29], [39]) and a lack of understanding (e.g., inconsistency in terminology [17], [38] or no shared understanding [17], [39]) are regarded as important related subcategories.

The category management refers to both a company's and a park's management which may be involved in facilitating industrial symbiosis. It describes barriers that first must be overcome internally by the company or park management in order to be ready for cooperation. This category consists of the factors commitment (e.g., lack of interest and engagement towards sustainable development (e.g., [8], [16], [28]) or the lack of behavioral change [38]), resources (e.g., lack of time (e.g., [14], [28], [31]) or lack of available and qualified personnel [15], [35], [40]). While the subcategory strategy in the category cooperation refers to the incompatibility of strategies of potential partners, strategy in the category management means that there are company-internal problems that prevent the implementation of industrial symbiosis (e.g., symbiosis may be misaligned with company's policies [19], the project is not channeled in the right way through the company [36] or inappropriate hierarchical organizational structure results in separated responsibilities and requires approval of corporate headquarters [29], [31]). Another subcategory is resistance from organizations (e.g., no willingness to risk existing supply chain [19] or aversion to change procedures and processes [14], [28]).

Knowledge-related barriers are first and foremost the lack of knowledge to identify and implement industrial symbiosis opportunities (e.g., technical [28], market [28] and environmental knowledge [31] or lack of expertise or experts (e.g., [8], [16], [33]) and lack of training (e.g., [31], [33], [39])) followed by awareness (e.g., unfamiliarity with industrial symbiosis concepts [33], [17], lack of recognition of waste as potential input [37] or unknown benefits [38]). Also, difficulty and lack of knowledge sharing (e.g., lack of mechanisms and methods to educate or learn [15], [17]) can hinder industrial symbiosis efforts.

Among the category information, the lack of information (e.g., limited information or accessibility on resource quality and quantity (e.g., [8], [19], [28]), collaboration methods [28] or inefficient information flows [16]) is the most prevalent factor. Other barriers are related to information sharing (e.g., general lack of information sharing (e.g., [8], [17], [31]) and resistance [16] or difficulty [15], [33] to do so), confidentiality issues (e.g., limited information disclosure due to confidentiality [13], [29], [34] or even unnecessary confidentiality [39]) and information systems (e.g., lack of or inadequate sustainability or management of information systems [29], [35]).

\subsection{Contextual factors}

The contextual factors (see Figure 4), accounting for 76 of all barriers (19\%), are related to policy/regulation applied (60 barriers) as well as the public/market surrounding the industrial symbiosis (16 barriers). 


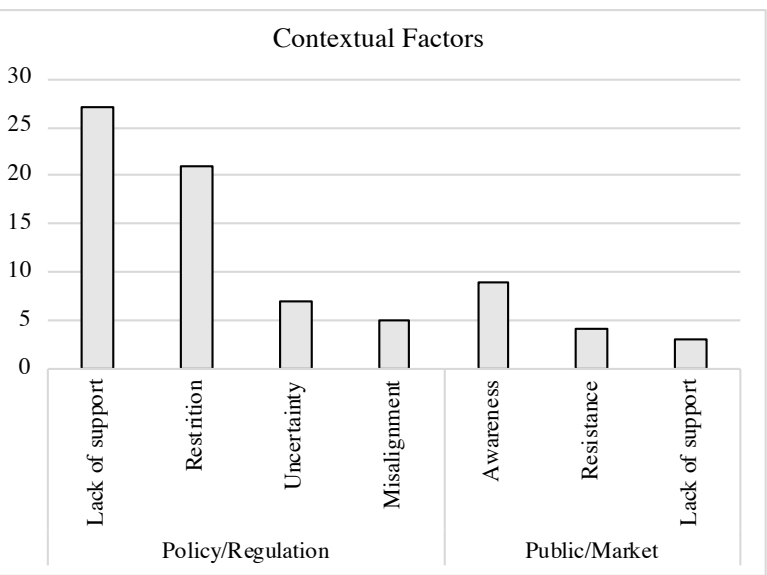

Figure 4. Number of barriers per category and subcategory for contextual factors

Lack of support is one major factor within the context of industrial symbiosis representing the category policy/regulation. Deficiencies of the regulatory framework [34], lacking support from public institutions [35] or absent/low landfill fee for nonhazardous wastes [34], [38] are related to that category. Another important subcategory are restrictions like outdated regulations, which do not support innovation [31], regulatory and bureaucratic issues [15] or restrictive definitions of waste and by-products [38]. Furthermore, uncertainty (e.g., regarding the legislation and regulation [8], [28], [31], [33]) and misalignment (e.g., cooperation between companies cannot be mandated by the government [16]) relate to that category.

Barriers related to the public/market surrounding the industrial symbiosis can be further categorized into awareness, resistance, and lack of support. Barriers related to awareness are, among others, lack of consumer interest in the environment [35] or lack of internal communication in municipalities [33]. Additionally, public and community actors [28] can also be barriers for industrial symbiosis when they show resistance. Also, the lack of stakeholders' involvement [16] or missing incentives by the market to reuse waste [38] can hinder industrial symbiosis.

\subsection{Interdependencies between factors}

As explained in section 3, although the goal of the qualitative content analysis was to assign each barrier to only one category/factor, some barriers had to be matched to multiple barrier categories. This applies, for example, to the aversion to cooperation and dependencies that can be caused either by the internal management of the company or by cooperation between different companies. Accordingly, they have been assigned to both categories. We extracted the barriers within multiple categories and counted the number of connections between different categories. These interdependencies are displayed in Figure 5. The strength of each line represents the number of connections between the depicted categories - the thicker the line, the stronger the connection. To clarify, a line between two categories means that at least one barrier is contained in both categories.

The size of the bubbles represents the number of barriers per category. While management and cooperation show the strongest interdependency, the financial and economic, information and cooperation as well as the policy/regulation and public/market category are also linked closely.

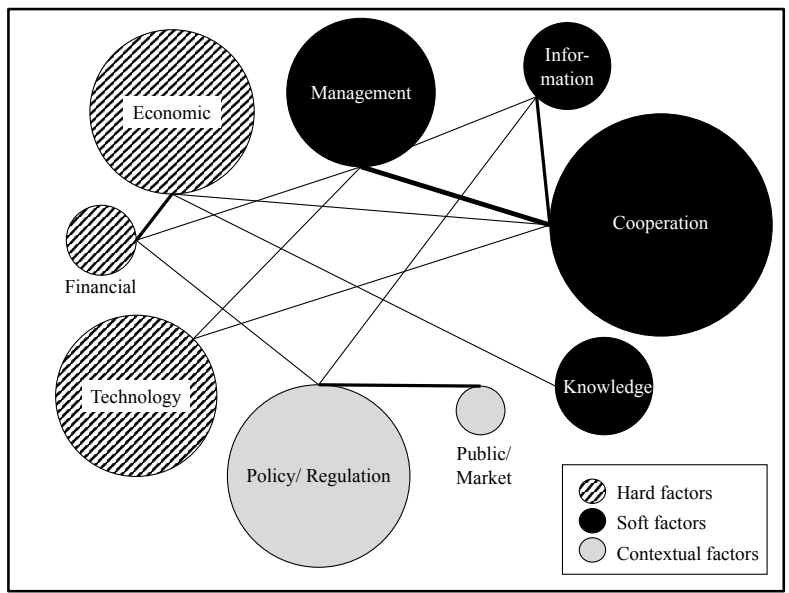

Figure 5. Interdependencies between barrier factors

Each category is interrelated with at least one and a maximum of four other categories within and beyond the classification of hard, soft, and contextual factors. This underlines the high interrelation between all categories and the complexity of barriers identified.

\subsection{Literature overview}

All in all, the different authors and studies include different types of barriers. To get a better overview of which barrier categories are included by which author, table 1 summarizes the findings in an author-centric overview. 
Table 1. Author-centric literature overview

\begin{tabular}{|c|c|c|c|c|c|c|c|c|c|}
\hline \multirow[b]{3}{*}{ 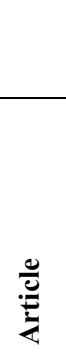 } & \multicolumn{9}{|c|}{ Factors } \\
\hline & \multicolumn{3}{|c|}{ Hard } & \multicolumn{4}{|c|}{ Soft } & \multicolumn{2}{|c|}{ Context } \\
\hline & 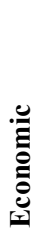 & 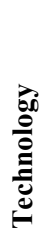 & 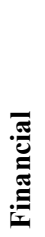 & 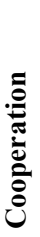 & 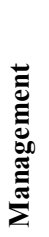 & 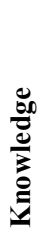 & & 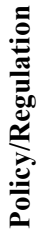 & 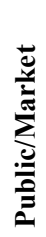 \\
\hline [8] & $\mathrm{x}$ & $\mathrm{x}$ & & $\mathrm{x}$ & $\mathrm{x}$ & $\mathrm{x}$ & $\mathrm{x}$ & $\mathrm{x}$ & $\mathrm{x}$ \\
\hline [9] & $\mathrm{x}$ & $\mathrm{x}$ & $\mathrm{x}$ & $\mathrm{x}$ & & & & $\mathrm{x}$ & \\
\hline [13] & $\mathrm{x}$ & $\mathrm{x}$ & & & $\mathrm{x}$ & & $\mathrm{x}$ & $\mathrm{x}$ & $\mathrm{x}$ \\
\hline [14] & $\mathrm{x}$ & $\mathrm{x}$ & & $\mathrm{x}$ & $\mathrm{x}$ & & & & \\
\hline [15] & $\mathrm{x}$ & $\mathrm{x}$ & $\mathrm{x}$ & $\mathrm{x}$ & $\mathrm{x}$ & $\mathrm{x}$ & $\mathrm{x}$ & $\mathrm{x}$ & $\mathrm{x}$ \\
\hline [16] & $\mathrm{x}$ & & $\mathrm{x}$ & $\mathrm{x}$ & $\mathrm{x}$ & $\mathrm{x}$ & $\mathrm{x}$ & $\mathrm{x}$ & $\mathrm{x}$ \\
\hline [17] & & $\mathrm{x}$ & $\mathrm{x}$ & $\mathrm{x}$ & $\mathrm{x}$ & $\mathrm{x}$ & $\mathrm{x}$ & $\mathrm{x}$ & \\
\hline [18] & & & & & $\mathrm{x}$ & & & & $\mathrm{x}$ \\
\hline [19] & $\mathrm{x}$ & $\mathrm{x}$ & $\mathrm{x}$ & $\mathrm{x}$ & $\mathrm{x}$ & & $\mathrm{x}$ & $\mathrm{x}$ & $\mathrm{x}$ \\
\hline [28] & $\mathrm{x}$ & $\mathrm{x}$ & $\mathrm{x}$ & $\mathrm{x}$ & $\mathrm{x}$ & $\mathrm{x}$ & $\mathrm{x}$ & $\mathrm{x}$ & $\mathrm{x}$ \\
\hline [29] & $\mathrm{x}$ & $\mathrm{x}$ & & $\mathrm{x}$ & $\mathrm{x}$ & $\mathrm{x}$ & $\mathrm{x}$ & $\mathrm{x}$ & \\
\hline [30] & $\mathrm{x}$ & $\mathrm{x}$ & $\mathrm{x}$ & & & & $\mathrm{x}$ & $\mathrm{x}$ & \\
\hline [31] & $\mathrm{x}$ & & $\mathrm{x}$ & $\mathrm{x}$ & $\mathrm{x}$ & $\mathrm{x}$ & $\mathrm{x}$ & $\mathrm{x}$ & $\mathrm{x}$ \\
\hline [32] & $\mathrm{x}$ & $\mathrm{x}$ & & $\mathrm{x}$ & & & & $\mathrm{x}$ & \\
\hline [33] & $\mathrm{x}$ & $\mathrm{x}$ & $\mathrm{x}$ & $\mathrm{x}$ & $\mathrm{x}$ & $\mathrm{x}$ & $\mathrm{x}$ & $\mathrm{x}$ & $\mathrm{x}$ \\
\hline [34] & $\mathrm{x}$ & $\mathrm{x}$ & & $\mathrm{x}$ & $\mathrm{x}$ & $\mathrm{x}$ & $\mathrm{x}$ & $\mathrm{x}$ & \\
\hline [35] & & $\mathrm{x}$ & $\mathrm{x}$ & & $\mathrm{x}$ & & & $\mathrm{x}$ & $\mathrm{x}$ \\
\hline [36] & $\mathrm{x}$ & $\mathrm{x}$ & $\mathrm{x}$ & $\mathrm{x}$ & $\mathrm{x}$ & $\mathrm{x}$ & & $\mathrm{x}$ & \\
\hline [37] & $\mathrm{x}$ & & $\mathrm{x}$ & $\mathrm{x}$ & $\mathrm{x}$ & $\mathrm{x}$ & $\mathrm{x}$ & & \\
\hline [38] & $\mathrm{x}$ & $\mathrm{x}$ & & $\mathrm{x}$ & $\mathrm{x}$ & $\mathrm{x}$ & $\mathrm{x}$ & $\mathrm{x}$ & $\mathrm{x}$ \\
\hline [39] & & $\mathrm{x}$ & $\mathrm{x}$ & $\mathrm{x}$ & & $\mathrm{x}$ & $\mathrm{x}$ & $\mathrm{x}$ & $\mathrm{x}$ \\
\hline [40] & $\mathrm{x}$ & $\mathrm{x}$ & & $\mathrm{x}$ & $\mathrm{x}$ & & & $x$ & \\
\hline [41] & $\mathrm{x}$ & $\mathrm{x}$ & & $\mathrm{x}$ & $\mathrm{x}$ & & $\mathrm{X}$ & $\mathrm{x}$ & \\
\hline
\end{tabular}

\section{Discussion}

\subsection{General Observations and Future Research}

Presenting the multitude of barriers, Section 4 shows how complex and challenging the implementation of industrial symbiosis is. In addition to industrial symbiosis, related sustainability concepts, such as sustainable supply chain management [32] and circular economy [35] were found in the literature, indicating that similar barriers may arise there as well.

The top three barrier categories are in descending order: cooperation, policy/regulation and management.
The high rank and interdependency between management and cooperation calls for a stronger consideration of organizational aspects, as both categories consist of primarily organizational, i.e., actor- and behavior-related, barriers causing a mismatch of the partners. Moreover, the presence of the subcategory strategy in both categories indicates that common or mutually beneficial sustainability business goals and processes must be developed between the partners. Only with a joint action by all actors can the respective barriers be overcome. Therefore, further research needs to propose concepts to determine and secure the necessary level of autonomy of each of the actors involved in order to satisfy each of the partners sufficiently. We also believe that there is a need for coordination mechanisms of the actors involved and their processes.

The fact that the category policy/regulation ranks second shows that a successful industrial symbiosis does not depend exclusively on industrial actors. Regulatory conditions (e.g., restrictive or misaligned policies) have a decisive impact on its implementation. We have noted, that this problem does not seem to be a country-specific one, as we have deliberately looked for all barriers, regardless of their setting and country. Some articles have identified barriers focusing on a specific country and others on a more general basis or without specifying the geographic region investigated. Among the regions investigated are Europe [14], [19] or European countries, such as Sweden [28], [41], Germany [14] or Spain [35]; Australia [13], [38], China [15], [30], Canada [31], Mauritius [34] or Egypt [16]. Further research should explicitly investigate how a regulatory framework could be designed to enable or support industrial symbiosis.

As mentioned above, it is important to investigate the interdependencies between different barriers. However, we could only identify one article that examines cause-effect relationships between barriers [17]. More attention should also be paid to the interaction between barriers and related categories. Though one solution will alleviate one or even several barriers, it may also reinforce other barriers. For example, the management barriers should not be considered alone without taking technological aspects into account which define the core processes of a company. In addition, we argue that further research is needed to measure the interdependencies of the barriers presented, in order to get a clearer picture on barriers that should be addressed together.

In addition, there is no study on the impact of barriers on the implementation of industrial symbiosis. Although studies exist, which measure the perception of barriers through interviews and surveys [14], [38], the results are mixed and their actual impact on the 
implementation of industrial symbiosis is not investigated. Possibilities to measure the impact of barriers would be useful in order to ultimately identify the most influential barriers.

Moreover, further studies on the identification of barriers should examine at which stage of industrial symbiosis lifecycle the barriers occur, which ones occur together, in which settings (e.g., type or size of industrial park) and which system elements are responsible. Additionally, future studies should also focus on the indepth analysis of each barrier identified, including their mitigation and how governmental and nongovernmental entities can support this mitigation.

Even though no hard factor ranks within the top three categories, the aspect of stable demand is the issue named most often in the categories related. The need for stable demand combined with the challenge to guarantee stable supply is inherent in the nature of industrial symbiosis concepts relying on by-product exchanges. However, this calls for a binding effect between industrial symbiosis partners to increase the industrial symbiosis' attractiveness. Business agreements on minimum possible stability within a certain period could increase activities between different actors and remove the insecurity of stability at least partly without triggering too much change in existing processes.

A glance at the barriers assigned to the soft factors shows that not only cooperation and management are of a strategic nature, but also the categories information and knowledge. As these barriers account for $49 \%$ of all barriers, this implies that business strategy of involved companies is a crucial element in industrial symbiosis. Accordingly, it is necessary to examine how new business processes serving sustainable development and industrial symbiosis can be integrated as easily as possible into existing businesses and industrial networks, especially against the background of limited personnel, time, budget, etc. Particular attention must be paid to the allocation of responsibilities, personnel and time resources. Against the background of information systems research, it is striking that these four barrier categories (cooperation, management, information, knowledge) can be tackled using tools (e.g., business process modeling) and ICT (e.g., groupware). However, current ICT supports primarily information and knowledge detached from management and cooperation. These tools could integrate approaches for project management or the design of business processes and models between the partners. Furthermore, current ICT for industrial symbiosis focuses more on information and knowledge exchange and less on their strategic embedding in the process of implementing industrial symbiosis and the coordination of information and knowledge flows [42]. This is in line with
Bengtsson and Ågerfalk [43], who see information systems as "change actant in sustainability innovation".

Furthermore, we want to highlight the potential of modeling and simulation to study complex systems [44], such as EIP. The wide range of potentially relevant aspects such as barriers and their interdependencies need to be considered in respective conceptual models. Currently, simulation models in industrial symbiosis primarily investigate eco-technological phenomena of the domain, followed by socio-economic interactions [45], each with a specific focus. To consolidate the findings and limitations of the individual simulation (models) a comprehensive model would be helpful. Such a model and simulation studies would also help to investigate the socio-technical aspects [44] that are introduced with the growing ICT support for industrial symbiosis adding a further layer of complexity.

\subsection{Limitations}

The limitations of this paper are mainly related to the methodology applied. The databases selected as well as the search terms applied limit the results. However, relevant databases were included and further search terms were checked for eligibility. Moreover, the qualitative content analysis [22] is a subjective procedure. Nevertheless, the categorization was done by both authors in discussion to avoid bias.

It should be noted that the analysis of barriers in this paper is based exclusively on the quantity of findings. Conclusions on the importance of barriers or categories are therefore based on the number of barriers.

\section{Conclusion}

Industrial symbiosis strongly supports the achievement of sustainable development goals. However, this support is currently hindered by a number of barriers in different areas. We have presented the industrial symbiosis as a concept that leads to complex systems, which is reflected in the vast number of barriers and the intertwining of the barriers among each other. Identifying and analyzing barriers for industrial symbiosis by means of a literature review and qualitative content analysis led to an overview of triggering factors for these barriers. The identified 402 barriers were categorized into nine categories: economic, technology, financial (hard, quantifiable factors), cooperation, management, knowledge, information (soft factors which are difficult to quantify), policy/regulation, and public/market (contextual factors). The high interrelations shown between the barrier categories call for a holistic consideration of industrial symbiosis barriers. Only if hard and soft factors are addressed in conjunction with the contextual 
factors surrounding the industrial symbiosis, an improvement of the current situation can be accomplished.

Besides an overview and analysis of existing barriers for industrial symbiosis, our findings led to aspects for further research which aim to create an even deeper understanding of barriers and interrelations in industrial symbiosis. Furthermore, our categorization highlighted the potential of ICT support to overcome barriers assigned to soft factors. ICT is not only able to support the exchange of information and knowledge, which is currently the focus, but also management and other cooperation processes.

Addressing the issues described in this paper may not only serve the implementation of industrial symbiosis but the general transition towards a more sustainable industry and society.

\section{Acknowledgements}

This work has been supported by the Federal Ministry of Economic Affairs and Energy of Germany within the framework of the 6th Energy Research Programme (grant no. 03ET4034).

\section{References}

[1] C. Yu, C. Davis, and G. P. J. Dijkema, 'Understanding the Evolution of Industrial Symbiosis Research: A Bibliometric and Network Analysis (1997-2012)', JIE, vol. 18, no. 2, pp. 280-293, 2014.

[2] M. Chertow and J. Park, 'Scholarship and Practice in Industrial Symbiosis: 1989-2014', in Taking Stock of Industrial Ecology, Springer, Cham, 2016, pp. 87-116.

[3] M. R. Chertow, “"Uncovering” industrial symbiosis', JIE, vol. 11 , no. 1, pp. 11-30, 2007.

[4] D. R. Lombardi and P. Laybourn, 'Redefining Industrial Symbiosis', JIE, vol. 16, no. 1, pp. 28-37, Feb. 2012.

[5] G. Massard and S. Erkman, 'A regional Industrial Symbiosis methodology and its implementation in Geneva, Switzerland', 2007.

[6] E. A. Lowe and L. K. Evans, 'Industrial ecology and industrial ecosystems', Journal of Cleaner Production, vol. 3, no. 1-2, pp. 47-53, Jan. 1995.

[7] H.-S. Park, E. R. Rene, S.-M. Choi, and A. S. F. Chiu, 'Strategies for sustainable development of industrial park in Ulsan, South Korea-From spontaneous evolution to systematic expansion of industrial symbiosis', Journal of Environmental Management, vol. 87, no. 1, pp. 1-13, Apr. 2008.

[8] A. Golev, G. D. Corder, and D. P. Giurco, 'Barriers to Industrial Symbiosis: Insights from the Use of a Maturity
Grid', Journal of Industrial Ecology, vol. 19, no. 1, pp. 141153, Feb. 2015.

[9] S. Yedla and H.-S. Park, 'Eco-industrial networking for sustainable development: review of issues and development strategies', Clean Technologies and Environmental Policy, vol. 19, no. 2, pp. 391-402, 2017.

[10] G. van Capelleveen, C. Amrit, and D. M. Yazan, 'A Literature Survey of Information Systems Facilitating the Identification of Industrial Symbiosis', in From Science to Society, Springer, Cham, 2018, pp. 155-169.

[11] M. Benedict, L. Kosmol, and W. Esswein, 'Designing Industrial Symbiosis Platforms - from Platform Ecosystems to Industrial Ecosystems', in PACIS 2018 Proceedings, Yokohama, Japan, 2018, pp. 26-30.

[12] Oxford Dictionaries, 'barrier | Definition of barrier in English by Oxford Dictionaries', Oxford Dictionaries | English. [Online]. Available: https://en.oxforddictionaries.com/definition/barrier.

[Accessed: 03-May-2018].

[13] D. Van Beers, G. Corder, A. Bossilkov, and R. Van Berkel, 'Industrial symbiosis in the Australian minerals industry: The cases of Kwinana and Gladstone', Journal of Industrial Ecology, vol. 11, no. 1, pp. 55-72, 2007.

[14] T. Domenech, R. Bleischwitz, A. Doranova, D. Panayotopoulos, and L. Roman, 'Mapping Industrial Symbiosis Development in Europe_typologies of networks, characteristics, performance and contribution to the Circular Economy', Resources, Conservation and Recycling, vol. 141, pp. 76-98, Feb. 2019.

[15] Q. Zhu, Y. Geng, J. Sarkis, and K.-H. Lai, 'Barriers to Promoting Eco-Industrial Parks Development in China: Perspectives from Senior Officials at National Industrial Parks', Journal of Industrial Ecology, vol. 19, no. 3, pp. 457467, 2015.

[16] D. Sakr, L. Baas, S. El-Haggar, and D. Huisingh, 'Critical success and limiting factors for eco-industrial parks: global trends and Egyptian context', Journal of Cleaner Production, vol. 19, no. 11, pp. 1158-1169, Jul. 2011.

[17] L. R. Bacudio et al., 'Analyzing barriers to implementing industrial symbiosis networks using DEMATEL', Sustainable Production and Consumption, vol. 7, pp. 57-65, Jul. 2016.

[18] I. Siskos and L. N. V. Wassenhove, 'Synergy Management Services Companies: A New Business Model for Industrial Park Operators', Journal of Industrial Ecology, vol. 21, no. 4, pp. 802-814, Aug. 2017.

[19] S. Menato, S. Carimati, E. Montini, P. Innocenti, L. Canetta, and M. Sorlini, 'Challenges for the adoption of industrial symbiosis approaches within industrial agglomerations', in 2017 International Conference on Engineering, Technology and Innovation (ICE/ITMC), Funchal, 2017, pp. 1293-1299. 
[20] L. Kosmol and W. Esswein, 'Capturing the Complexity of Industrial Symbiosis', in Advances and New Trends in Environmental Informatics, 2018, pp. 183-197.

[21] J. Webster and R. T. Watson, 'Analyzing the Past to Prepare for the Future: Writing a Literature Review', MIS Quarterly, vol. 26, no. 2, pp. xiii-xxiii, 2002.

[22] P. Mayring, 'Qualitative Content Analysis', Forum: Qualitative Social Research, vol. 2, no. 1, pp. 1-10, 2000.

[23] C. Haskins, 'A Systems Engineering Framework for EcoIndustrial Park Formation', Systems Engineering, vol. 10, no. 1, pp. 83-97, Mar. 2007.

[24] B. M. Sopha, A. M. Fet, M. M. Keitsch, and C. Haskins, 'Using systems engineering to create a framework for evaluating industrial symbiosis options', Syst. Engin., vol. 13, no. 2, pp. 149-160, 2010.

[25] G. B. Grant, T. P. Seager, G. Massard, and L. Nies, 'Information and Communication Technology for Industrial Symbiosis', JIE, vol. 14, no. 5, pp. 740-753, Oct. 2010.

[26] A. Maqbool, F. Mendez Alva, and G. Van Eetvelde, 'An Assessment of European Information Technology Tools to Support Industrial Symbiosis', Sustainability, vol. 11, no. 1, p. 131, Dec. 2018.

[27] D. Moher, A. Liberati, J. Tetzlaff, and D. G. Altman, 'Preferred reporting items for systematic reviews and metaanalyses: the PRISMA statement', BMJ, vol. 339, Jul. 2009.

[28] G. Aid, M. Eklund, S. Anderberg, and L. Baas, 'Expanding roles for the Swedish waste management sector in inter-organizational resource management', Resources, Conservation and Recycling, vol. 124, pp. 85-97, 2017.

[29] W. Fichtner, I. Tietze-Stöckinger, M. Frank, and O. Rentz, 'Barriers of interorganisational environmental management: two case studies on industrial symbiosis', Progress in Industrial Ecology, vol. 2, no. 1, pp. 73-88, 2005.

[30] L. Fraccascia, 'Industrial symbiosis and urban areas: A systematic literature review and future research directions', Procedia Environmental Science, Engineering and Management, vol. 5, no. 2, pp. 73-83, 2018.

[31] R. LeBlanc, C. Tranchant, Y. Gagnon, and R. Côté, 'Potential for Eco-Industrial Park Development in Moncton, New Brunswick (Canada): A Comparative Analysis', Sustainability, vol. 8, no. 5, p. 472, May 2016.

[32] J. Li, S.-Y. Pan, H. Kim, J. H. Linn, and P.-C. Chiang, 'Building green supply chains in eco-industrial parks towards a green economy: Barriers and strategies', Journal of Environmental Management, vol. 162, pp. 158-170, 2015.

[33] J. K. Madsen, N. Boisen, L. U. Nielsen, and L. H. Tackmann, 'Industrial Symbiosis Exchanges: Developing a Guideline to Companies', Waste and Biomass Valorization, vol. 6, no. 5, pp. 855-864, 2015.
[34] S. Mauthoor, 'Uncovering industrial symbiosis potentials in a small island developing state: The case study of Mauritius', Journal of Cleaner Production, vol. 147, pp. 506$513,2017$.

[35] M. Ormazabal, V. Prieto-Sandoval, R. Puga-Leal, and C. Jaca, 'Circular Economy in Spanish SMEs: Challenges and opportunities', Journal of Cleaner Production, vol. 185, pp. 157-167, Jun. 2018.

[36] S. Päivärinne, O. Hjelm, and S. Gustafsson, 'Excess heat supply collaborations within the district heating sector: Drivers and barriers', Journal of Renewable and Sustainable Energy, vol. 7, no. 3, p. 033117, May 2015.

[37] J. Patricio, L. Axelsson, S. Blomé, and L. Rosado, 'Enabling industrial symbiosis collaborations between SMEs from a regional perspective', Journal of Cleaner Production, vol. 202, pp. 1120-1130, Nov. 2018.

[38] W. Stubbs, 'Exploration of barriers to mainstreaming industrial ecosystems in Australia', PIE, vol. 8, no. 4, p. 319, 2014.

[39] B. T. Teh, C. S. Ho, Y. Matsuoka, L. W. Chau, and K. Gomi, 'Determinant factors of industrial symbiosis: Greening Pasir Gudang industrial park', presented at the IOP Conference Series: Earth and Environmental Science, 2014, vol. 18.

[40] J. L. Walls and R. L. Paquin, 'Organizational Perspectives of Industrial Symbiosis: A Review and Synthesis', Organization and Environment, vol. 28, no. 1, pp. 32-53, 2015.

[41] A. Wolf, M. Eklund, and M. Söderström, 'Towards cooperation in industrial symbiosis: considering the importance of the human dimension', Progress in Industrial Ecology, vol. 2, no. 2, pp. 185-199, 2005.

[42] L. Kosmol, 'Sharing is Caring - Information and Knowledge in Industrial Symbiosis: A Systematic Review', in 2019 IEEE 21st Conference on Business Informatics (CBI), Moscow, Russia, 2019, vol. 01, pp. 21-30.

[43] F. Bengtsson and P. J. Ågerfalk, 'Information technology as a change actant in sustainability innovation: Insights from Uppsala', The Journal of Strategic Information Systems, vol. 20, no. 1, pp. 96-112, Mar. 2011.

[44] J. Beese, M. K. Haki, S. Aier, and R. Winter, 'SimulationBased Research in Information Systems', Bus Inf Syst Eng, vol. 61, no. 4, pp. 503-521, Aug. 2019.

[45] M. Maiwald, L. Kosmol, C. Pieper, and T. Schmidt, 'ESProNet: A Model Library for the Dynamic Simulation of Industrial Symbiosis', presented at the AMMS 2019, Prague, Czech Republic, 2019. 